\title{
虫生微生物及其利用
}

曾 省

植物保护是防治农、林作物病虫害, 保 证丰产、稳产的有效途径之一，所以 “农业 八字宪法”列有 “保”字，其中包括人工、化 学、物理、农业、生物、法规(植物检疫)等 防治方法。而生物防治是常被采用的方法之 一, 效果有时很显著, 如利用天然界益兽、 益鸟、天敌昆虫(包括捕食性昆虫、寄生蜂、 寄生䗉等)、线虫及微生物等。用以防治的 微生物有病毒、细菌、真菌及原生动物等。

每种害虫在自然界中都有不少的微生物 天敌，同它们生在一处，互相制约，造成“自 然平衡”的局面。其中牵涉內在、外在因子 很多, 有自然的力量, 也有人为的力量; 有 生物因素，也有非生物因素; 而气候因子与 它们的关系最为密切。毛主席在《实践论》中 教导我们: “抓着了世界的规律性的认识， 必须把它再回到改造世界的实践中去, 再用 到生产的实践、革命的阶级斗爭和民族斗爭 的实践以及科学实验的实践中去。”因此, 我 们不仅要探索害虫和天敌与其它因子的关 系, 而且还要进一步利用与改造它们。

控制自然、消灭害虫有许多方法, 过去 一般只注意化学防治。化学防治害虫虽然见 效很快、处理方便, 但是有许多地方因为长 期地不合理施萂,已引起不少不良后果:（1）
害虫产生抗药性; (2) 这种害虫杀死后, 別 种害虫又起来, 因为別种害虫的天敌被药杀 死;（3）殘毒遗留积累于蔬荣及果品中，有 害于人、畜健康;（4）制莉原料量大, 有供 不应求之势。有人认为, 以生物防治害虫是 “无限资源”替代“有限资源”，因为天敌在建 立擘落之后, 㶌生蔓延, 世代不绝, 而用化 学䓎剂防治, 有时很快就消失了。

生物防治是利用有生命的动物、植物来 灭虫, 受外界环境条件影响很大, 若施用时 期或方法不合适, 则还不如化学药剂防治效 果显著。因此, 采用生物防治, 事先进行广 派、哚入的调查, 进行多方试验, 摸清特性 和规律, 创造大量繁殖与制造菌剂的方法, 以及改进使用技术等, 确是一系列关键性问 题。现在把国內外利用微生物防治害虫已有 的实例介绍于下, 以说明该项研究工作有很 大的前途。

\section{一 利用细菌防治害虫}

利用细菌来抑制害虫, 世界各地事例很 多, 限于篇幅, 仅提已被广泛利用, 而且成 效显著的几种。

（1）日本金蛂(金龟子)流乳病 ${ }^{[1]}[\mathrm{Milky}$ disease of Japanese beetle (Popillia japonica 
Newm) ], 包括有两种细菌, 臫日本金蛂芽 狍杆菌 (Bacillus popilliae Dutky) 与慢死芽 孢杆菌 (B. lentimorbus Dutky)。蛴螬(金龟 子幼虫) 被此菌感染后, 血液混浊, 全体呈 乳白色。健虫血渥暴露于空气中郎变暗色, 而病虫的血滴却仍保持白色。美国 (19391949）曾使用该菌菌粉 151,559 磅，撒布于 73,618 英亩面积草地上, 每平方呎虫口密度 由 44 头減至 5 头以下。我国金龟子种类很 多,成虫把果树、林木的叶吃光, 危害很大, 幼虫为害禾苗亦甚烈。迄今用化学䒺剂防治 还未奏全功, 且用䓎量很大。因此, 在我国 蛴螬体中找出流乳病杆菌, 加以培美利用, 是很重要的。

（2）苏芸金杆菌 ${ }^{[2]}$ (Bacillus thuringiensis Berliner) 是柏利纳 (Berliner) 1951 年从地中 海粉螟 (Ephestia kühniella) 中分离出来的, 是一种产芽孢细菌，又是一种严格的虫生细 菌。它能抵抗不良环境, 杀虫力强, 可引起 不同鳞翅目幼虫流行病。现在我国正在研究 利用它来消灭大面积的松毛虫。

（3）蜡样芽孢杆菌 (Bacillus cereus Fr. \& Fr. $)^{[1]}$ 郎青虫菌或称虫菌 3 号 (B. cereus var. galleriae, No. 3) 能引起许多鳞翅目昆 虫败血病 (Septicemia)。也有奇生于壁蛋体 內的, 对白荣青虫、蜜蜂蜡蛽感染力很強。 1959年该菌由国外引进, 现湖北省农业科学 研究所研究此菌, 汉口抗生素厂已生产大量 菌粉, 以此喷杀白㭉青虫与松毛虫颇著成效。 1962 年作者从辽宁凤城四台子土中采到腐 烂、出水、发臭的柞䖽奇生䗉 (Crossocosmia tibialis Chao) 蛹內亦分离*出这样芽抱杆菌 (图 1)。

(4) 蝗疫杆菌 ${ }^{[1]}$ [Aerobacter (Coccobacillus) aerogenes var. acridiorum] 系德勒尔
（d'Herelle）1910年在墨西歌发现和应用，成 绩颇著, 但后来別人依法使用失败。这可能 是蝗属不同或本菌种有几个菌系或小种 (Strains）存在，因此毒力不同。

\section{图 1 从柞亘奇生䗉病蛹分离出来的芽抱杆菌}
A. 蜡样芽孢杆菌 (Bacillus cereus)
B. 巨大芽玸杆菌 (Bacillus megatherium)

(5) 赛氏红菌 ${ }^{[3] （ S e r r a t i a ~ m a r c e s c e n s ~}$ Bizio）在国外能侵害许多鳞翅目昆虫，最近 陈誉在新疆首次从自然死亡甜荣像鼻虫 (Bothynoderes punctiventris Germ) P体中分离 出来, 经接种试验, 对黄地老虎 (Agrotis segetum) 死亡率为 $90 \%$ ，对甘蓝夜蛾 (Barathra brassicae)、棉龄虫 (Heliothis armigera) 也都

\footnotetext{
* 本工作是沈阳农学院张义成同志在中国农业科学院 植物保护研究所进行的, 由何礼远闰志指导, 并由 北京农业大学俞大紘教授指导鉴定。
} 
有致病力。

\section{二 利用以菌防治害虫}

从农业与医学方面来看，早就知道買菌 （Fungi）能广泛为害植物和动物, 但引起昆 虫病害则知之较少。1853年白西 (A. Bassi) 发现家委有白㖰病菌寄生, 而中国发现更早, 在1578年以前就利用“冬虫夏草”、“鲂查”、 “蝉花”等食虫菌入荺。侵害昆虫的買菌有下 列几大类:

（1）藻状菌纲 (Phycomycetes) 中有以 下几属，郎虫霖 (Empusa，分生孢子梗不分 枝)、虫生藻菌属 (Entomophthora, 分生狍子 梗分枝) 及绵露属（Achlya）。作者（19541956）在河南洛阳一带曾发现小麦吸浆虫幼 虫夏天常被一种绵星所侵害 (图 2)。过去国

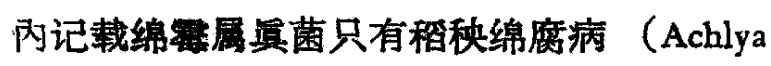
oryza I. et N. 与 A. prolifera De Bary), 而 国外交献记载这属的置菌供害水中动物达十 余种 ${ }^{[4]}$ 。

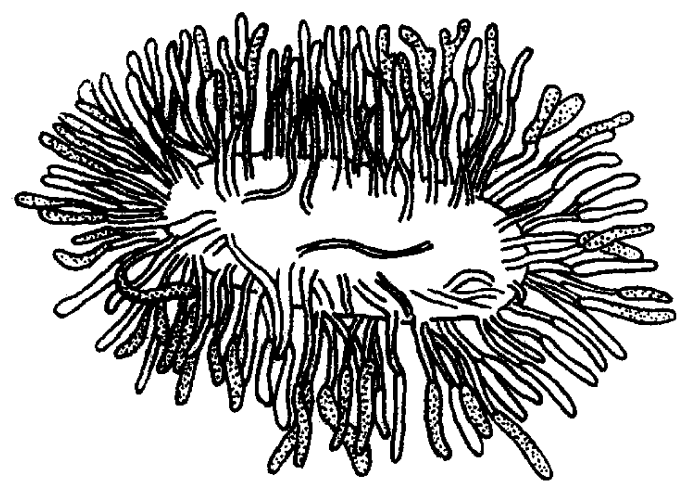

图 2 麦红吸浆虫幼虫被绵霖 (Achlya sp.) 所寄生的外观

（2）子露菌纲 (Ascomycetes) 有虫草菌 属 (Cordyceps) 郎“冬虫夏草”一类的虫生真 菌，邓叔萧年 ${ }^{[5]}$ 在《中国的真菌》一书中列举 24种c 此外还有多毛菌属 (Hirsutella) ${ }^{[6]}$ 寄
生于鳞翅或鞘翅目昆虫身上。1964 年河南 舞阳县农林局奇来被该菌寄生的金针虫标 本，据说该县金针虫沟吒头虫（Pleonomus canaliculatus F.）发生严重，每本方尺有虫 3-15 头， 个別地块被寄生 率达 60-70\% (图 3)。

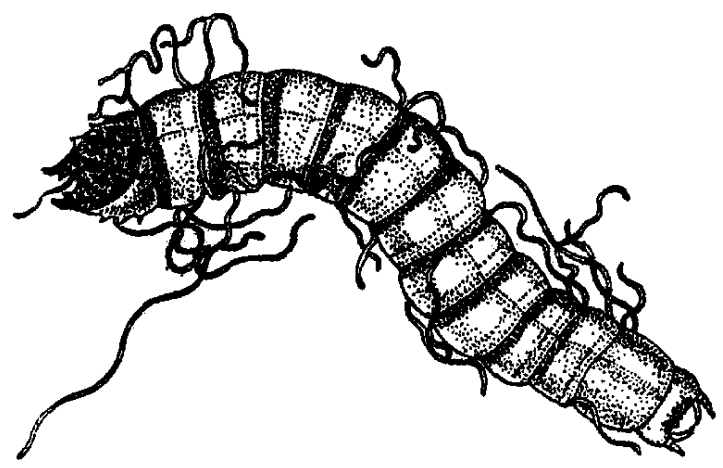

图 3 沟金针虫被一种多毛菌 (Hirsutella sp.) 所奇生，体外围生分生拖子梗束

（3）担子菌纲（Basidiomycetes）有时虽 能侵害昆虫，但扭不重要，从略。

(4) 牛知菌纲 ${ }^{[1,6] \text { (Deuteromycetes) 中 }}$ 有许多属是重要的虫生真菌, 例如: 1. 粉䩶 赤坐霖属（Aschersonia）多寄生于介壳虫与 粉䖪 ( $A$. aleyrodis Webber), 孢子堆是红色 的, A. goldiana Sacc. \& Ellis 是黃色的;

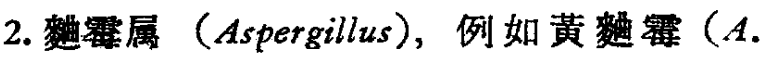
flavus Link）侵害望蜂幼虫。1964 年在北京 室內饲养蝼蛄, 死亡频繁, 体上亦长出一种 䴵籍，似 $A$. oryzae Wehmer；3．白殭菌属 (Beauveria)，国內徐庆丰 ${ }^{[7]}$ 邓庄、林伯欣 等研究较详, 褔建林业科学研究所 ${ }^{[8]}$ 已大量 培养, 以此喷杀松毛虫有效。此外, 还有 4. 镰 刀菌 (Fusarium)；5．棒束孢菌属（Isaria）； 6. 绿㽝菌属 (Metarrhizium, 青木清认为与 Oospora 是同物异名); 7. 堆生孢子菌属 Sorosporella)； 8. 穗状菌属（Spicaria）等。 


\section{三 利用病繁防治害虫}

据世界文献记载, 昆虫病毒到现在已有 250 余种。绝大多数系侵害鳞翅目昆虫 ${ }^{[1,3]}$, 少 数也能感染膜趐目和双翅目幼虫。但鞘翅目、 半翅目昆虫具有高度抵抗性。幼虫最易感染 (有时蛹也能偶然感染), 到了成虫期, 昆虫 组织內改变为不感病性, 这是生物学上极有 兴趣的问题。病毒系纯奇生性的微生物, 不能 在没有活细胞基质上生长, 主要生于细胞核 內, 也有生于细胞质內。病毒在普通显微镜下 看不到任何形象, 用电子显微镜才能看出包 含体 (Inclusion bodies) 內病毒的形状和结构。 昆虫病毒至少可分为 4 类 $^{[1,3]}: 1$. 多角体形包 含体, 是波莱尔氏属 (Borrelina), 发育于细 胞核內的，呆“核型多角体病瑇”，发育于细 胞质內的叫“质型多角体病毒”; 2. 有微小椭 圆形颗粒状包含体，或称葫状体 (Capsules), 在细胞核或细胞质中发育, 是勃戈提氏属 (Bergoldia); 3, 有折光性而具多态型 (Polymorphic) 的包含体是巴约氏属 (Paillotella); 4.不具有任何包含体, 是莫拉塔属 (Morator)。 此外还有史密斯氏属 (Smithia), 该属仅有一 个模式种, 包含体是多角形, 病毒粒子是圆 形。病害在昆虫体內有一定潛伏期, 直至某 些环境条件改变时而刺激其活动与发育, 高 温 $\left(32-35^{\circ} \mathrm{C}\right)$ 、饥饿或营养不良易打破昆虫 抗病毒性, 而缩短其潛伏期, 病逐爆发。

病毒各种包含体不溶解于热水、冷水、 酒精、氯仿、乙醚、二甲苯及丙酮，但易溶 解于碱液。所以辽宁省推广防止柞䖽脓病一 种病毒时, 是用 $1 \%$ 苛性钠溶液, 保持 $16-$ $18^{\circ} \mathrm{C}$ 卵面消毒（把卵装在纱布袋里，先用水 洗 2-3 分钟, 浸䓎一分钟, 立郎取出, 用 手轻轻挤出药水, 然后放清水中漂洗二、三
次, 至无萂液为止, 然后晾干, 保温在 $18-$ $20^{\circ} \mathrm{C}$ 中，促使卵餒化）。在室內饲养，为了 保证不发病毒，用 $0.5 \%$ 石灰水浸叶消瑇， 取出晾干喂䖽, 都是应用这个特性来消灭柞 亘病毒的。

目前各国利用人工方法散布病毒防治害 虫的例子还不多, 原因是生产大量病毒有困 难。在实验室內生产大量病毒有二种方法:

1. 组织培养法 (Tissue culture)；2. 昆虫饲 养室的生产法 (Insectary production)。近年 来实验证明, 受精鳮蛋是组织培养哺乳类动 物病毒的好物质与方法, 但是欲生产大量病 毒用作田间散布, 还是以饲养大量昆虫奇主 来培养病毒最有希望 ${ }^{[1]}$ 。一种方法是收集早 期感染的田间寄主昆虫, 放置在实验室或昆 虫饲育室中, 直到发病死亡, 就可用昆虫户 体制造病毒浮悬液 (Virus suspension); 另一 种方法是从田间采集大量健全的幼虫, 然后 连同必须的食料放在适当构造的虫笼中，于 食料上喷射微量的病毒浮悬液, 或放置少数 带病毒昆虫于其中, 则全部幼虫不久就被侵 染。在这些昆虫死后, 收集起来, 制成浮量 液, 然后放于适当地方聍藏或冷藏。这种浮 悬液用于田间时，须稀释至每毫升含有 5 千 万至 1 亿的多角体才适于喷撒。

\section{四 利用原生动物防治贵虫}

昆虫的病由原生动物㟢生所致是很多 的, 其中主要的是属于微抱子虫目 (Microsporidia)。巴约 (Paillot, 1928) 曾说过:“原 生动物在害虫自然控制中所起的作用比细菌 更重要得多。”奇生于经济昆虫不下 30 余种, 著名例子有玉米螟微孢子虫 (Perezia pyraustae)、荣白蝶微抱子虫 (Perezia mesnili, $P$. legeri, P. pieris 及 Thelohania mesnili)、 
苹果蛾微孢子虫 (Nosema carpocapsae) 及棉 铃虫狍子虫 (Nosema heliotidis) 等, 利用之 能引起害虫慢性病，而使虫口低落。问锦 曾 ${ }^{[9]}$ 于 1962-1963 年首次在北京玉米蛽体 內找到微孢子虫而定名为 Nosema pyraustae (Paillot) Weiser, 观察其发育。

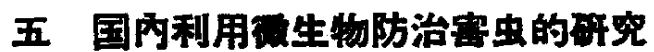

我国过去对寄生昆虫的微生物研究 很 少，但贯彻科学研究为生产服务的方针后， 对徽生物杀虫剂研究颇多，发展很快。例如：

（1）苏芸金杆菌和青虫菌的利用，经中 国科学院、林业科学研究院、湖北省农业科 学研究所、湖南细菌肥料厂及农业部成都兽 医生物獭品制造厂和四川省农业科学院等单 位努力研究，摸索出生产两种菌剂的一套工 艺流程，每克菌粉含菌量达 300 亿以上。用 来杀除马尾松松毛虫、荣青虫效果显著, 施 之于茶毛虫及果树害虫也有效。

（2）白㽬菌的利用，自从吉林省农业科 学院 ${ }^{[2]}$ 开始研究利用白殭菌来防治大豆食心 虫 (Grapholitha glycinivorella Matsumura) 得成功后，溷引起各方的注意，但是否在野外 柞林为害柞虫，还须樑入调查和试验。据广 西方面报导，松毛虫感染白軩菌，死尸在树 皮煡隙中隐藏历三年，孢子仍有生活力。福 建林业科学研究所 ${ }^{[8]}$ 经 5 年室內和林间试验 研究，证明该菌在适温 $\left(24-28^{\circ} \mathrm{C}\right)$ 、高湿 $(\mathrm{R} \cdot \mathrm{H} \cdot 90 \%)$ 情况下, 对防除松毛虫有一定效 果,死亡率达 50.8-88.2\%，且具有瞢延扩散 能力，对人畜无害。1964年在武汉全国生物 防除学术讨论会上, 讨论在养䖽地区使用白 殬菌孢子喷杀森林害虫问题，一位寔病专家 声称：家香在室內饲美，因已掌握了“防殭 粉”，因此对白殂病判不可怕，而在不养䖽
地区防治农林害虫，使用白殂菌更不成问题 了。不过白殭菌孢子发芽，湿度要在 $90 \%$ 以上，且施用地点、季节及时间倒値得事先 仔细调查研究。

\section{B \\ 图 4}

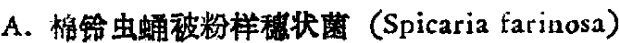
所窎生，上生不同形状的分生抱子梗束和块;

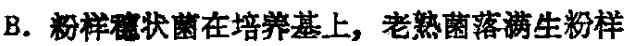
分生孢子

（3）两种穂状菌的发现和试用。粉样穗 状菌 [Spicaria farinosa (Fron) Vuill] (图4) 和赤色穗状菌 [Spicaria fumoso-rosea (Wize) vassilijevsky] (图5)在国內为首次记载。前者 
由作者在北京从棉铃虫蛹体中分离出来 ${ }^{[10]}$; 后者是作者在辽宁风城四台子从柞亘寄生䗉 (Crossocosmia tibialis Chao) 蛹体中分离出 来 ${ }^{[11]}$ 。这两种菌的寄坠范围较广, 毒性強,

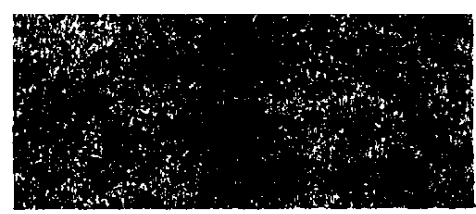

A

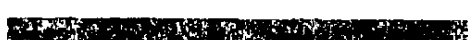

图 5

A. 作虫等生蜎蛹在土中自然感染赤色穗状菌 后所生出棒状分生孢子梗束;

B. 柞虫寄生䗉蛹经人工接种赤色䅼状菌孢子 后用沕洞培粦，各蛹体发生分生狍子梗束

而且容易培养。1964年在武汉全国生物防除 学术讨论会上，经作者报告后，有许多专家 建议应大量培养孢子，作杀害地下虫试验， 因为这两种菌能在马、羊、猪数与萛宿士、 荷池泥培养基上生长, 賏试杀地下夜蛾科害 虫蛹与蛔蛹, 效率颇高, 而且土中温、湿度
变迁较缓, 特別是灌激或低窪地区, 土中湿 度高, 有利于这些菌发芽、威染、生长。现 正沿此途径摸索进行各种试验。

其他虫生具菌如:(4)蚜霸(Empusa sp.), 上海复旦大学生物学系曾进行研究; (5)虫 生藻菌 (Entomophthora sp.), 马永贵曾在三 化蛽体上发现, 并加以研究; (6)绿殭菌 $(M e-$ tarrhizium spp.) 在內蒙古、贵州、四川发 现,都未大面积应用于生产; (7)还有一种喽 红色堆生孢子菌 [Sorosporella uvella (Krass) Giard] 为贵州福泉烟草研究所发现, 为害几 种地老虎很普遍。

\section{六 存在问题和今后努力方向}

（1）关于苏芸金杆菌和青虫菌菌粉 制 造产品含菌数的检查与毒力测定, 应有一致 的操作规程与统一标准。欲适于国家大量生 产，应积极寻找多种寄主和扩大使用范围; 同时也必须改变其由于不同寄圭所引起菌种 专化性的偏向, 并注意经常透过复壮（活体 培养）加強其生活力。改进工艺流程，減低 成本, 增加毒力, 以提高防治效率。芽孢细 菌培养过滤液经各方试验,证明有杀虫毒素, 应加测定，设法提炼利用。

（2）利用虫生真菌防治农林害虫的问题 是如何能产生大量狍子：1. 用固体培养应研 究培养基的成分与配合，以利大量繁殖，形 掌握多产狍子的技术。最理想的是, 利用牲畜 肥料或堆肥于发酵后，在不消畫情况下，汼 入冥菌狍子，使其自能生存、发展，一遇地 下害虫, 因环境条件适宜, 孢子发芽, 侵入 虫体, 因而致死。这一关必须突破; 2. 用液 体深层培养也须先在室內试验，求得合理的 氮、碳源比例，控制空气流通量和酸碱度，使 其多产孢子。另外，利用滤液提炼与用填充刘 
吸附滤渣, 晾干研细, 进行杀虫等试验。

（3）利用病毒防治害虫在我国还没人做 试验，更谈不上大量应用。目前国內昆虫病 毒研究仅限于以下两方面：1. 室內理论性的 研究，如病分窉、鉴定、结构观察、组织 培养和潛伏性、感染性的试验，以及在虫体 中所起生理、生物化学变动的现象；2. 只局 限于䖽体病毒的研究，做了各种消毒、防病 试验。今后希望针对生产，扩火应用范围， 大胆営试，大量培养病瑇来消灭猖獗、暴食 性的害虫。

（4）为了达到上述各项要求, 必须组 织协作，集中力量，迅速解决生产上的迫切 问题。组织协作，在社会主义国家內是提高 科学水平、增加生产的多快好省的办法。同 时也须用各种方式培养研究技术人员，建立
一支队伍。此外, 还须组织力量, 进行调 查，采集研究，挖掘资源，大量利用，扑灭 害虫，以保证农业稳产、丰产。

[1] Steinhaus E. A., Principles of insect pathology, 300-364, 398-495, 504-622, McGraw-Hill, 1949.

[2] DeBach P. Schlinger E. I., Biological control of insect pests and weeds, 515-534, Chapman \& Hall Ltd., 1964.

[3] SWeetman H. L., The principles of biological control, 30-41, 42-57, 58-68, 1958.

[4] 青木清, 昆虫病理学, 43-93、107-177、178一 181，技拫常，1957。

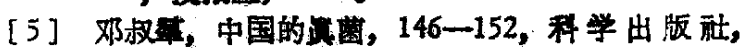
1963。

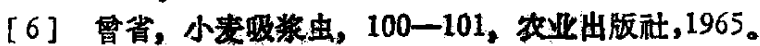

[7] 徐庆丰, 昆虫学报, 9 [3], 203-217 (1959)。

[8] 福建林业科学研究所报皆, 1964。

[9] 问锦曾, 动物学报, 17 [1], 64 (1965)。

[10] 曾省, 噪物保护学报, 1 [3], 332-333 (1962)。

[11] 賏省, 棭物保护学报, 4 [1], 59-68(1965)。

\title{
超声診断的評价及其发展
}

\author{
徐智 章 \\ （上海第一医学院中山医院超声诊断室）
}

超声诊断是一门年轻的学科。从开始至 今, 仅有 20 多年。1942年 Dussik ${ }^{[1]}$ 最先把 超声用于医学诊断,但所用的为穿透式, 从观 察超声赛娍程度诊断脑肿瘤。1951 年有几 个作者同时开始使用回波反射式 $\mathrm{A}$ 型仪于监 床诊断, 如 French、Wild ${ }^{[2]}$ 等研究脑出血、 脑肿瘦，Ludwig 等研究胆石。1952 年起,
Howry $^{[3]}$ 首先研究超声显象, 用 $\mathrm{B}$ 型或复 合圆周扫描; 1958 年 Donald、Mac Vicar 与 Brown ${ }^{[4]}$ 等报导 BP 型对妇产科疾病的显象。 1956 年 Hertz、Edler ${ }^{[3]}$ 进行了超声心动图的 研究。1 1957 年里村茂夫 ${ }^{[6]}$ 首先用超声多普 勒仪研究心肚壁与渡膜的运动; 1959 年里村 茂夫 ${ }^{[7]}$ 又用超声多普勒法研究了血管运动。 